\title{
BOUNDARY LAYER POLLUTION PROFILES FROM A RURAL SITE IN SOUTH KOREA
}

\author{
John Sullivan ${ }^{1 *}$, Thomas McGee ${ }^{1}$, Anne Thompson ${ }^{2}$, Laurence Twigg ${ }^{3}$, Grant Sumnicht ${ }^{3}$, Ryan \\ Stauffer ${ }^{1}$
}

${ }^{1}$ Atmospheric Chemistry and Dynamics Laboratory, NASA Goddard Space Flight Center, Greenbelt, MD 20771 USA, *Email: john.t.sullivan@nasa.gov

${ }^{2}$ Earth Sciences Division, NASA Goddard Space Flight Center, Greenbelt, MD 20771 USA

${ }^{3}$ Science Systems and Applications Inc., Lanham, MD 20706 USA

\begin{abstract}
During the NASA 2016 KORUS-AQ campaign, the ground based NASA GSFC ozone lidar and balloon borne instrumentation were deployed to the remote Taehwa Forest site $(37.3 \mathrm{~N}, 127.3 \mathrm{E}$, $151 \mathrm{~m} \mathrm{AGL}$ ) to characterize the transport of pollution downwind of the Seoul metropolitan region. On most days from 02 May to 10 June 2016, continuous hours of lidar profiles of ozone were measured. Select days are shown to represent key ozone events that occurred at the rural site.
\end{abstract}

\section{INTRODUCTION}

In order to better assess pollution emission sources and plume evolution in Asia, there has been an international effort to launch the Geostationary Environmental Monitoring Spectrometer (GEMS) to provide hourly measurements of key pollutants (e.g. ozone; nitrogen dioxide $\left(\mathrm{NO}_{2}\right)$; sulfur dioxide $\left(\mathrm{SO}_{2}\right)$; particulate matter) over the Korean peninsula and the Asia-Pacific region. As a precursor to the Korean GEMS satellite launch and to further investigate the vertical distribution of pollutants impacting South Korea, the United States (U.S.) National Aeronautics and Space Administration (NASA) and the Korean Ministry of the Environment/Korean National Institute of Environmental Research (NIER) conducted an international cooperative field experiment, entitled the Korea-U.S. Air Quality (KORUS-AQ, https://espo.nasa.gov/home/korus-

aq/content/KORUS-AQ) study. The campaign was designed to probe pollutants (and chemical gradients) throughout the entire Korean peninsula using specifically designed aircraft flight patterns, ground based measurements (in situ and remotely sensed, and model simulations. The work herein mainly utilizes the synergy of available data to focus on high ozone events at a downwind from Seoul $(30 \mathrm{~km}$ southeast, Figure 1a) rural site (Taehwa Research Forest, TRF).

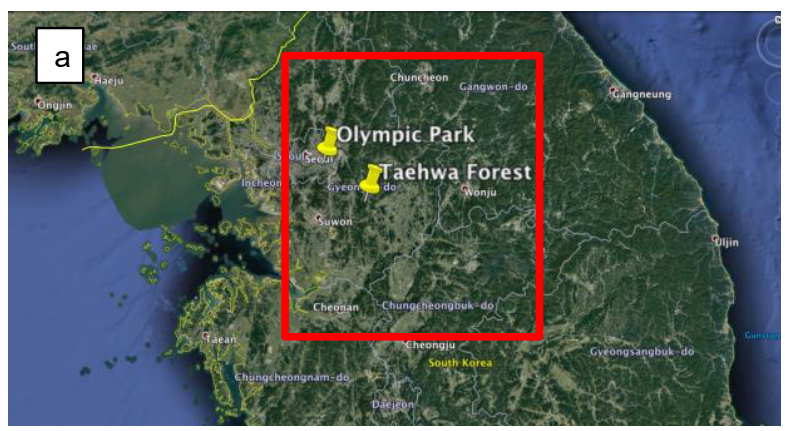

Figure 1: Map of South Korea and the Taehwa Forest site (TRF).

\section{OBSERVATIONS}

\subsection{Ozonesondes}

An unprecedented $\mathrm{O}_{3}$-sonde record, which were conditioned and prepared with current community standards [1], was recorded at TRF throughout the KORUS-AQ study from 10 May to 12 June. Afternoon soundings (13:30 to $16: 30 \mathrm{KST})$ of $\mathrm{O}_{3}$ (top panel, Figure 2) and temperature (bottom panel, Figure 2) illustrate day-to-day variability at TRF. The two case studies (17 May and 09 June) are highlighted with black boxes.

There were large disparities in boundary layer $\mathrm{O}_{3}$ throughout the campaign period. From 10-16 May, concentrations were mostly between 70-80 ppb, which were associated with cooler temperatures and higher synoptic wind speeds. However by the early afternoon of 17 May, a 
stagnant high-pressure system located over the Yellow Sea ushered in warmer air, calmer winds, and clearer skies. For the remainder of the campaign until 03 June, a similar meteorological system was preserved, providing favorable conditions for rapid $\mathrm{O}_{3}$ production of concentrations above 120 ppbv. On 04 and 06 June, mixed precipitation events occurred, limiting $\mathrm{O}_{3}$ production in the surrounding days. However, by 9-10 June another high-pressure system approached the region, increasing temperatures, stagnating winds, and fostering $\mathrm{O}_{3}$ production.

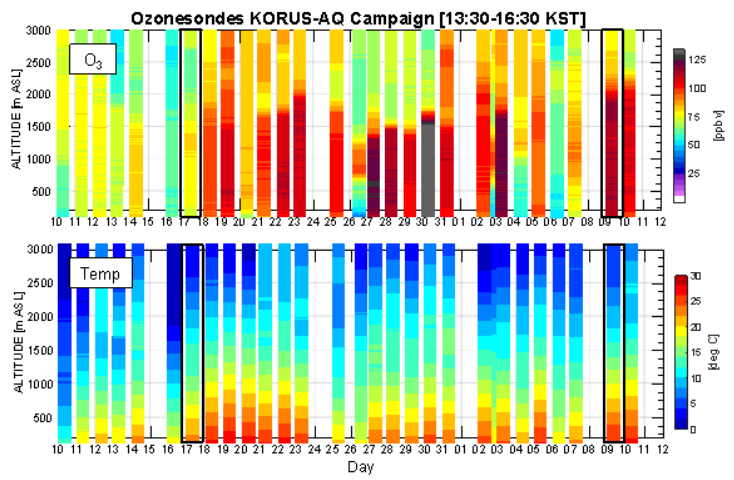

Figure 2: Afternoon soundings (13:30 to 16:30 KST) of $\mathrm{O}_{3}$ (top panel) and temperature (bottom panel) illustrate day-to-day variability at TRF from 10 May to 12 June.

\subsection{GSFC Ozone DIAL}

Vertical profiles of $\mathrm{O}_{3}$ were measured using the NASA Goddard Space Flight Center TROPospheric OZone Differential Absorption Lidar (GSFC TROPOZ DIAL or TROPOZ [2]) in support of the KORUS-AQ study. The TROPOZ system, a charter NASA instrument in the Tropospheric Ozone Lidar Network (TOLNet, http://www-air.larc.nasa.gov/missions/TOLNet/), derives $\mathrm{O}_{3}$ concentrations to mostly within 10$15 \%$ as compared to nearby $\mathrm{O}_{3}$-sonde profiles [3] and has been previously utilized to characterize $\mathrm{O}_{3}$ episodes such as stratospheric-tropospheric exchange [4], terrain driven recirculation/transport events $[5,6]$, and regional transport events. During the field study at TRF, the TROPOZ was operated nearly continuously in order to understand subhourly (15-min) variability of $\mathrm{O}_{3}$ during the early morning, afternoon, and evening hours. Figure 3 includes several days where the lidar was operated continuously for 9-13 hrs and illustrates the key $\mathrm{O}_{3}$ features systematically observed at TRF during the campaign. To add context with auxiliary measurements, each of the TROPOZ measurement days has the 1-min in situ GSFC $\mathrm{O}_{3}$ monitor (Thermo 49i) data in the lowest bin, a dashed-line solar curve, and coincident ozone soundings previously reported in Figure 2.

\section{RESULTS}

During every morning at TRF between 07:00-08:00 KST, the surface ozone monitor observed low $(<10$ ppbv $)$ surface $\mathrm{O}_{3}$ concentrations. Low early morning values are associated with a stable surface layer, in which surface frictional effects and titration of $\mathrm{O}_{3}$ occur. Additionally, TROPOZ measurements in six of the eight days in Figure 4 indicate residual layering of $\mathrm{O}_{3}$ above the stable surface layer with concentrations above 75 ppbv between 08:00 and 10:00 KST. This $\mathrm{O}_{3}$ resides between 500 and 1500 $\mathrm{m}$ ASL, and is related to the extent of vertical mixing during the previous day's planetary boundary growth and decay. An example of residual layer height corresponding to the previous day's ozone mixing height and concentrations is demonstrated in the 9-10 June observations. $\mathrm{O}_{3}$ with concentrations near 100 ppbv are mixed to near $1700 \mathrm{~m}$ ASL by 19:00 KST and result in a residual layer residing at nearly the same height the following morning (as corroborated by the $\mathrm{O}_{3}$ sonde on 10 June).

As solar radiation and convective mixing increase in the late morning hours (after 11:00 KST), surface concentrations of $\mathrm{O}_{3}$ generally began to be more representative of concentrations measured aloft from the TROPOZ. During this time, boundary layer growth appears to entrain the residual layer(s) of pollutants helping to increase mid-day $\mathrm{O}_{3}$ concentrations (e.g. 17-18 May, 9-10 June). Until 14:00 KST, boundary layer $\mathrm{O}_{3}$ concentrations are mostly between 65-85 ppbv. However, as solar radiation decreases after 14:00 KST most days observe a large (10-40 ppbv) and generally well-mixed contribution of $\mathrm{O}_{3}$ transported to the site. During all days, $\mathrm{O}_{3}$ concentrations aloft on each day are above 90 


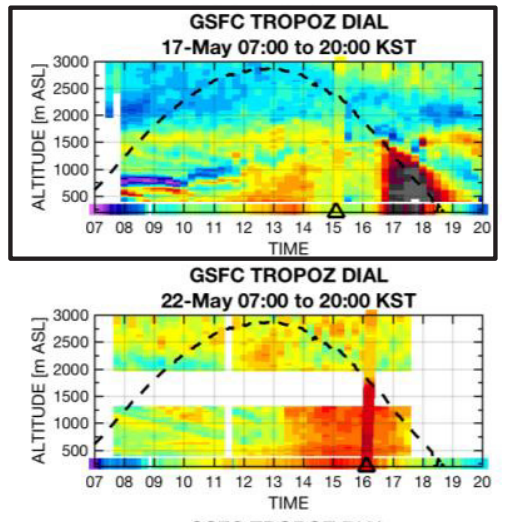

GSFC TROPOZ DIAL

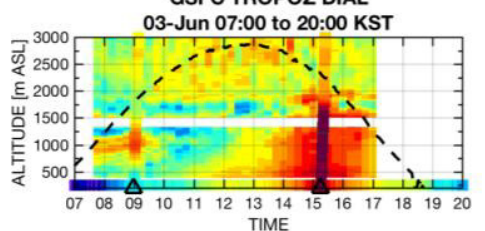

GSFC TROPOZ DIAL

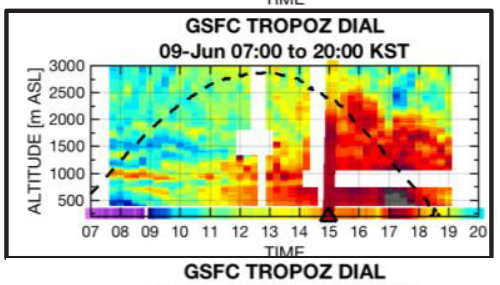

18-May 07:00 to 20:00 KS

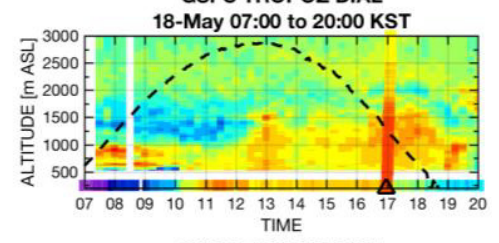

GSFC TROPOZ DIAL

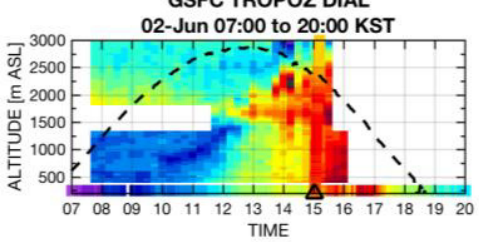

GSFC TROPOZ DIAL

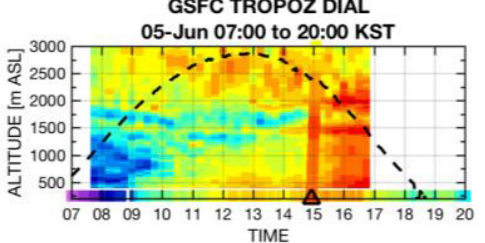

GSFC TROPOZ DIAL

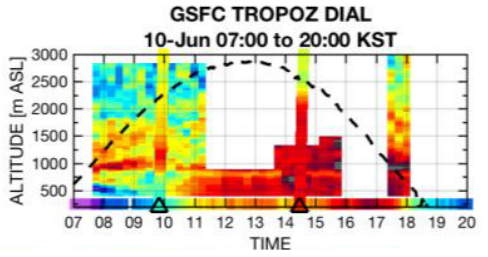

Figure 3: Ozone Lidar Profiles during the KORUS-AQ campaign period. ppbv after 17:00 KST and several days are higher than 120 ppbv.

As solar radiation diminishes near 19:00 KST, 17 May, 18 May, and 09 June have observations that continue for several hours. During each of these measurement times after 19:00 KST, $\mathrm{O}_{3}$ concentrations aloft are significantly larger (4060 ppbv) than the coincident surface concentrations, indicating the rapid depletion and titration of surface ozone from local emissions. This process then results in the polluted aloft residual layer during nighttime hours that will be mixed down on the following morning to enhance the pollution budget.

\section{CONCLUSIONS}

Several days of nearly continuous ozone lidar observations have yielded a novel assessment of pollution reaching TRF and other rural sites in South Korea. Several case studies indicate rural sites may be experiencing long-term negative effects of $\mathrm{O}_{3}$ (which are associated with much worse health and agricultural effects) and therefore more stringent domestic regulatory controls on $\mathrm{O}_{3}$ precursors.

\section{ACKNOWLEDGEMENT}

Unless otherwise noted, all ozone lidar data used in this study can be found in the KORUS-AQ data archive (http://wwwair.larc.nasa.gov/missions/korus-aq/). This research was supported by appointments to the NASA/USRA Postdoctoral Program at the Goddard Space Flight Center Atmospheric Chemistry and Dynamics Laboratory. The authors gratefully acknowledge support provided by the NASA Tropospheric Chemistry Program and the Tropospheric Ozone Lidar Network (TOLNet).

\section{REFERENCES}

[1] Thompson, Anne M., Jacquelyn C. Witte, Herman GJ Smit, Samuel J. Oltmans, Bryan J. Johnson, Volker WJH Kirchhoff, and Francis J. Schmidlin. "Southern Hemisphere Additional $\mathrm{O}_{3}$ sondes 
(SHADOZ) 1998-2004 tropical $\mathrm{O}_{3}$ climatology: $3 . \quad$ Instrumentation, station-to-station variability, and evaluation with simulated flight profiles." Journal of Geophysical Research: Atmospheres (1984-2012) 112, no. D3 (2007).

[2] Sullivan, J. T., T. J. McGee, G. K. Sumnicht, L. W. Twigg, and R. M. Hoff. "A mobile differential absorption lidar to measure sub-hourly fluctuation of tropospheric $\mathrm{O}_{3}$ profiles in the BaltimoreWashington, DC region."Atmospheric Measurement Techniques 7, no. 10 (2014): 3529-3548.

[3] Sullivan, John T., Thomas J. McGee, Russell DeYoung, Laurence W. Twigg, Grant K. Sumnicht, Denis Pliutau, Travis Knepp, and William Carrion. "Results from the NASA GSFC and $\mathrm{LaRC} \mathrm{O}_{3}$ lidar intercomparison: New mobile tools for atmospheric research." Journal of Atmospheric and Oceanic Technology 32, no. 10 (2015a): 1779-1795.

[4] Sullivan, John T., Thomas J. McGee, Anne M. Thompson, R. Bradley Pierce, Grant K. Sumnicht, Laurence W. Twigg, Edwin Eloranta, and Raymond M. Hoff. "Characterizing the lifetime and occurrence of stratospheric-tropospheric exchange events in the Rocky Mountain region using high-resolution ozone measurements." Journal of Geophysical Research: Atmospheres 120, no. 24 (2015b): 12410-12424.

[5] Sullivan, J. T., et al. (2016), Quantifying the contribution of thermally driven recirculation to a high-ozone event along the Colorado Front Range using lidar, J. Geophys. Res. Atmos., 121, doi:10.1002/2016JD025229.

[6] Sullivan J. T., et al. (2017), Lidar observations revealing transport of $\mathrm{O}_{3}$ in the presence of a nocturnal low-level jet: Regional implications for "next-day" pollution". Submitted to Atmospheric Environment, 11 Nov 2016. 